\title{
El edificio para el Batallón Pichincha de Cali (1906-1968)*
}

The Building for the Battalion Pichincha Cali (1906-1968)

\section{Jorge Galindo Díaz \\ Laura María Henao Montoya}

\section{Resumen}

A partir de la reconstrucción histórica del proceso de levantamiento de un edificio como lo fue el del Batallón Pichincha, se explica la forma como la ciudad de Cali orientó su desarrollo urbano hacia la margen norte del río que lleva su nombre. La primera parte de este artículo trata de los antecedentes morfológicos de la ciudad y de la manera como la construcción del llamado puente de calicanto permitió expandir el centro histórico hacia el norte como parte de un propósito de integración entre la ciudad y el río. La segunda parte describe el proceso constructivo del edificio castrense para desde allí explicar la transformación de su entorno inmediato y cómo se generó un nuevo modelo de expansión urbana.

Palabras clave: historia, militares, urbanismo, río Cali.

\section{Abstract}

From the historical reconstruction of the constructive process of a building (the battalion Pichincha), it explains the shape that the city of Cali guided its urban development toward the north border of the river who carries its name (Cali). The first part of this article is about the morphological background of the city and how the techniques of masonry arch bridge allowed expand the historical center toward the north in order to integrate the city and the river. The second part describes the constructive process of the military building; from here it explains the transformation of its immediate environment and the same time it generated a new model of urban expansion.

Keywords: Construction History, military buildings, urban history Cali, Cali river.

\section{Arquitectura y estructura urbana de Cali hasta fines del siglo XIX}

Desde su fundación (en torno a 1536) y prácticamente hasta 1750, Cali presentó un lento crecimiento físico y demográfico que solo experimentaría una aceleración en la segunda mitad del siglo XVIII cuando la ciudad empezó a gozar de una notoria mejoría en sus condiciones económicas explicada-entre otras cosas- por la consolidación de una incipiente red de caminos que permitía a

- Fecha de recepción del artículo: 14-01-2013 • Fecha de aceptación: 14-04-2013

JORGE GALINDO DÍAZ. Arquitecto de la Universidad del Valle. Doctor en Arquitectura, Universidad Politécnica de Catalunya. Profesor Titular de la Universidad Nacional de Colombia, sede Manizales. Correo electrónico: jagalindod@unal.edu.co. LAURA MARÍA HENAO MONTOYA. Arquitecta de la Universidad Nacional de Colombia, sede Manizales. Correo electrónico: laurah-991@hotmail.com.

* Este artículo de investigación científica y tecnológica en arquitectura y urbanismo es uno de los resultados del proyecto de fortalecimiento a grupos de investigación GTA en hábitat y tecnología, línea estudios en cultura técnica del hábitat construido, financiado por la Dirección Nacional de Investigaciones de la Universidad Nacional de Colombia. Convocatoria 2012-2013. 
sus habitantes desplazarse bien fuese hacia el sur en dirección a Popayán, hacia el norte en busca de Yumbo, Vijes o Roldanillo, hacia el oriente para cruzar el río Cauca y llegar hasta las haciendas ubicadas en la otra banda o hacia el occidente para remontar la cordillera y descender desde allí por sus ríos en busca del puerto de Buenaventura sobre el océano Pacífico. Gracias a ello la minería y el comercio local se dinamizaron y numerosos grupos de artesanos ganaron presencia en la vida pública generando así un transitorio estado de prosperidad.

Como bien lo han demostrado importantes autores (Colmenares, 1976; Aprile, 1991 y Vásquez, 1982, principalmente) durante ese período la ciudad se fue transformando lentamente al punto que dejó de ser un conjunto de fincas caseras dispuestas en una traza que configuraban un villaje ordenado sobre la base de una concepción eminentemente utilitaria (Aprile, 2010, p. 31), para convertirse en un núcleo urbano más compacto. Sin embargo, su silueta era todavía eminentemente horizontal propia del siglo XVIII, resultado de una expansión producida desde el centro hacia el sur de la plaza mayor (convertida en plaza de mercado en 1674) y caracterizada entre otras cosas por la continua subdivisión de los predios urbanos y la densificación constructiva de las manzanas.

En la segunda mitad del siglo XVIII ocurren nuevos y significativos hechos que afectan la vida cotidiana de la ciudad, entre los que se cuentan la construcción del primer hospital en 1752 y de la fábrica de licores en 1780 (Aprile, 1991). Pero serán los edificios religiosos y la red de pilas públicas repartidas por la ciudad para abastecer de agua a sus habitantes, los grandes logros arquitectónicos y urbanísticos de la época. Y así, tanto la iglesia de San Francisco (edificada casi por completo en ladrillo cocido) como los conventos de San Agustín, La Merced, Santo Domingo y San Juan de Dios fueron cediendo al espacio público pequenas plazoletas frente a sus atrios que contribuían a desahogar las angostas calles sin empedrar del centro de Cali.

En cualquier caso, la vida urbana seguía girando en torno a la plaza mayor y desde ella partían las calles más importantes mientras las manzanas se iban extendiendo hacia el sur y el oriente con base en un mismo modelo geométrico. De esta manera, las vías no empezaban en las riberas del río Cali, lo cual hacía que entre el río y la traza urbana se conformara un espacio residual que en últimas se convertía en patio o sementera de las casas de habitación cuyas fachadas se alineaban sobre la carrera tercera. La ciudad no solo se negaba morfológica y espacialmente a la presencia del río, sino que además se mostraba incapaz de atravesarlo mediante una obra duradera que permitiera comunicar su centro urbano con los terrenos cultivables del lado norte.

Para 1808 la ciudad contaba ya con cuatro barrios dentro del recinto urbano (Aprile, 2010) que sumaban unas 172 manzanas y alojaban casi siete mil habitantes repartidos en unas 1.151 casas (Figura 1). Los barrios respondían a los nombres de La Merced (o Nuestra Señora de las Mercedes), San Agustín, San Nicolás y Santa Rosa (también llamado San Francisco). La mayor parte de esas casas eran de uso residencial o mixto, construidas con materiales diversos aunque con predominio del bahareque sobre el adobe y el barro cocido (Aprile, 2010). Es decir, las técnicas que a principios del siglo XIX dominaban los artesanos de la construcción en Cali se concentraban en el manejo de fibras vegetales, la carpintería de madera, la mampostería de adobes y el embutido de muros, lo que dejaba un reducido campo para aquellos que pretendían manejar con habilidad la pega de ladrillos cocidos en horno haciendo uso de morteros elaborados a partir de cal y arena. Cobra, entonces, importancia el hecho de que el templo de San Francisco, construido alrededor de 1773 bajo la dirección del quiteño Fernando de Larrea y enteramente hecho en ladrillo, se constituyera en la primera escuela práctica del arte de la albañilería en la ciudad. Lamentablemente no se tiene documentación de primera mano que dé cuenta de los aspectos técnicos y constructivos que confluyeron en su edificación.

De todas maneras, los principios más simples de la mecánica llevan a pensar que se priorizaban los sistemas adintelados (viga-columna o viga-muro de carga) sobre los sistemas en los que hicieran presencia el arco, la bóveda o la cúpula. Tampoco existen registros que den fe de manera detallada de las técnicas constructivas que entonces se usaban en la ciudad en las que primaba un quehacer de corte artesanal que no contaba con la participación de ingenieros, arquitectos o alarifes cualificados. 
Figura 1

Traza urbana y perímetro de Cali a comienzos del siglo XIX

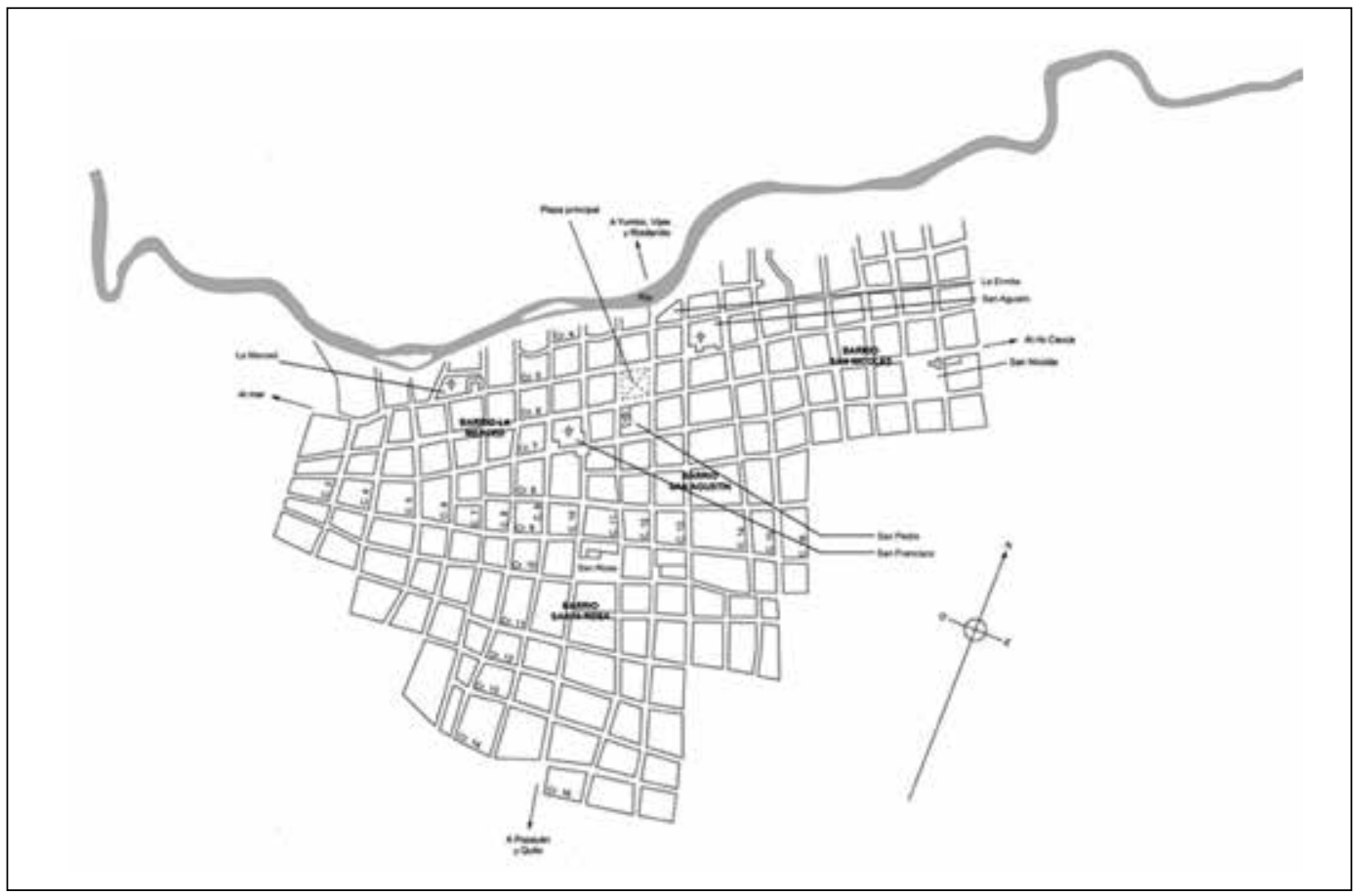

Fuente: elaboración propia a partir de Aprile (2010).

Así, la tarea de construir un puente duradero sobre el río Cali constituyó sin duda un punto de inflexión en las prácticas constructivas locales.

\section{La construcción del puente de calicanto sobre el río Cali}

Aunque es fácil suponer que desde el período colonial los habitantes de Cali deseaban contar con un puente duradero que les permitiera cruzar el río en un punto cercano a la plaza principal, no fue sino hasta 1825 cuando mediante acta del Concejo se comisionó al regidor decano para que obligase a los vecinos del lugar a construir un puente de guaduas sobre el río de la ciudad (Archivo Histórico de Cali: Actas del Concejo, t. 43, f. 312). Sin embargo, y pese a la buena voluntad del Concejo de la ciudad los recursos económicos eran escasos debido a largos años de lucha por la Independencia que habían dejado las arcas prácticamente vacías. Quizás por ello, en 1830 el mismo Concejo se vio en la necesidad de apelar al apoyo público en forma de raciones para los obreros (Archivo Histórico de Cali: Actas del Concejo, t. 44, ff. 769-769v) y en 1833 se consideró la posibilidad de hacer una construcción provisional empleando troncos de guaduas (Archivo Histórico de Cali: Actas del Concejo, t. 52, ff. 34-35), la cual probablemente se llevó a cabo ese mismo año.

Pero los ciudadanos deseaban una obra duradera. En abril de 1834 luego de que una creciente arrasara la débil estructura de guadua, el jefe político José María Caicedo fijó un plazo de diez meses a fin de reunir la cantidad necesaria para emprender un proyecto de trascendental importancia para la ciudad, así se tuviese que recurrir a la figura de un empréstito respaldado por las exiguas rentas municipales (Archivo Histórico de Cali: Actas del Concejo, t. 53, ff. 26-27, 414). Lo cierto es que para 1835 se dio comienzo a los trabajos de construcción del puente de mampostería sobre el río Cali bajo la coordinación de una comisión de ciudadanos nombrados para tal fin. En febrero de ese mismo año, José María Caicedo rendía al Concejo un informe relativo al estado de las obras y en mayo se presentó un balance contable de lo ejecutado (Archivo Histórico de Cali: Actas del Concejo, t. 53, ff. 33-35). En octubre se designó al señor Pío Rengifo como reemplazo de Caicedo (Archivo Histórico de Cali: Actas del Concejo, 
t. 55, ff. 7-8v) de cuya dimisión al frente de los trabajos del puente no se conocen las causas.

Ese intenso año terminaría con un hecho de singular importancia: el ciudadano José Montehermoso fue nombrado director de las obras de la estructura de calicanto (Buenaventura, 1957). Su nombre ya era conocido gracias al papel desempeñado como maestro en la construcción de los templos de San Francisco y San Pedro y probablemente su verdadera función era no solo considerar una traza inicial del puente sino también llevar a cabo la supervisión técnica de las labores que una obra de esta naturaleza comprendía: desde el replanteo sobre el terreno hasta la construcción de los pavimentos y desagües, pasando por la cimentación dentro y fuera del agua, la consolidación de los rellenos artificiales entre los tímpanos, la preparación de las mezclas de mortero para la pega de las mamposterías y el cimbrado y descimbrado de los arcos y las bóvedas.

Sobre la marcha misma de los trabajos de construcción el Concejo de Cali tuvo que perfeccionar el modelo administrativo a fin de llevar a feliz término la obra. Si consideramos cierto lo que expresa Buenaventura (1957, p. 163) en relación con la permanencia de Montehermoso durante todo el proceso constructivo desde su vinculación en 1835 hasta la puesta en servicio del puente (diez años después), se puede deducir que a medida que la obra avanzaba él asumió cada vez con mayor intensidad las labores de naturaleza técnica y dejó el espacio vacante para la figura de un director administrativo que solo ejercería funciones en 1842 con la llegada del sacerdote franciscano fray Ignacio Ortiz (Buenaventura, 1957), quien también venía de participar en los trabajos de reconstrucción de la iglesia de San Pedro.

Si se tiene en cuenta que para 1845 el puente sobre el río Cali ya estaba en servicio, es fácil deducir que los tres ańos de labores del sacerdote Ortiz estuvieron concentrados en la construcción de los arcos principales situados sobre el lecho del río y en la manera como estos se apoyaban sobre el estribo sur que conectaba la obra con la Calle 12 y a través de ella con la plaza central de la ciudad. También como parte de la construcción del puente de calicanto, Montehermoso u Ortiz (o ambos) vieron la necesidad de desviar el curso del río aguas arriba, dando origen así a un nuevo cauce que se llamó río Nuevo. Entre ambos cursos (el antiguo y el nuevo) se dejó una franja de terreno en donde años después se asentaría el edificio destinado al Batallón Pichincha.

\section{La ciudad y el río a lo largo del siglo XIX}

Relatos de viajeros y cronistas como Holton (1857), Pérez (1863), André (1884) y Rivera y Garrido (1886) describen a la Cali de la segunda mitad del siglo XIX como una ciudad compacta y ordenada en la que el río y el puente que lo cruza hacían parte importante de su imagen. Además, anotan la presencia de lavanderas y bañistas que aprovechaban los amplios espacios que formaba su cauce-a los que llamaban comúnmente "charcos"para llevar a cabo sus labores de lavado o recrearse en sus aguas. Entre estas pozas se destacaban el Charco del Burro (donde hoy está el museo La Tertulia), el Charco de la Estaca (desde donde salía el llamado río Nuevo), el Charco de La Merced (detrás del convento del mismo nombre), el Charco del Colorado Caicedo (detrás de las antiguas salas de cine) y el Charco de La Ermita (frente a la capilla levantada en el siglo XVII).

Sin embargo, el río no siempre era un remanso de aguas tranquilas al que los habitantes de Cali podían aproximarse con confianza. Un cronista local relata una terrible avenida acontecida en junio de 1893 en la que las aguas del río Cali y las del río Nuevo se juntaron y su nivel subió por encima de un metro de la clave de los grandes arcos (Buenaventura, 1957, pp. 169-170). Años más tarde, se mencionan otras crecientes similares sin que se hubiesen presentado desgracias personales que lamentar (Correo del Valle, No. 174, junio 9 de 1904) pero que obligaron a pensar en la necesidad de canalizar el río, al menos en el tramo en que este era todavía tangencial a la ciudad.

Fue la construcción del puente de calicanto lo que favoreció las iniciativas orientadas a ocupar las tierras de la margen norte del río (Palacios, 1896). Así, en 1859 se construyó un pequeño puente de albañilería sobre el río Nuevo y entre este y el de calicanto se levantó un camellón que en 1872 continuó en dirección hacia el río Aguacatal, en busca del camino hacia el mar. En 1889 se construyó un segundo camellón que del puente del río Nuevo 
seguía para la vía del norte (Palacios, 1896, p. 59), labor que estuvo a cargo de un batallón del ejército, anticipando con ello la construcción de numerosos proyectos en la ciudad. Una reconstrucción planimétrica del sector se puede apreciar en la Figura 2.

Así, para finales del siglo XIX, el eje formado por los extremos de los puentes de albañilería del río Cali y del río Nuevo, el cual estaba flanqueado por cuatro enormes ceibas (y que se conocería después como Paseo de las Ceibas) empezaba a ser mirado con mentalidad paisajística. Hacia el occidente del camellón se construyó el Parque Bolívar (denominado así desde 1883 según información contenida en El Cauca, 23 de septiembre de 1897), un espacio ajardinado que constituyó la antesala de un nuevo e importante edificio, el primero de gran escala que se levantó en la margen norte del río Cali. A su vez, este parque hacía parte de un proyecto más ambicioso conocido entre los caleños como Plaza de Bolívar en homenaje al Libertador en las conmemoraciones del primer centenario de la Independencia, adyacente al también Parque Mallarino o Parque Isaacs que ocupó la franja de terreno situada entre el nuevo edificio para el Batallón y el río Cali.

\section{La construcción de un edificio para el Batallón Pichincha}

En los albores del nuevo siglo, el gobierno presidencial del general Rafael Reyes (1904-1909) abogó entre otras cosas por la modernización del Ejército colombiano a través de la instauración de colonias militares y penales, la creación de importantes instituciones como la Escuela Militar y la Escuela Naval y la división del territorio en zonas castrenses. Como parte de esta política se creó en 1908 el Comando de la Tercera Brigada, organizado en principio por dos unidades: el Batallón Número 10 de Infantería con asiento en Popayán, y el Regimiento de Infantería Pichincha, acantonado en Cali (Anónimo, 1978).

Como parte de esta actitud reformista también atribuye Vásquez (2001) la necesidad de construir una sede para el cuartel en la ciudad de Cali en los terrenos conocidos como La Pesebrera, de propiedad del general Jaime Córdova y situados en el globo de terreno llamado La isla comprendido entre el río Cali y el río Nuevo. El nombre obedecía al hecho de que en 1906 en lo que entonces era la Plaza de Bolívar -es decir, entre el puente de mampostería y el del río Nuevo- se dispusieron unas caballerizas en donde los viajeros que llegaban

Figura 2

Plano del sector central de la ciudad y del área colindante al puente de calicanto (c.a. 1915)

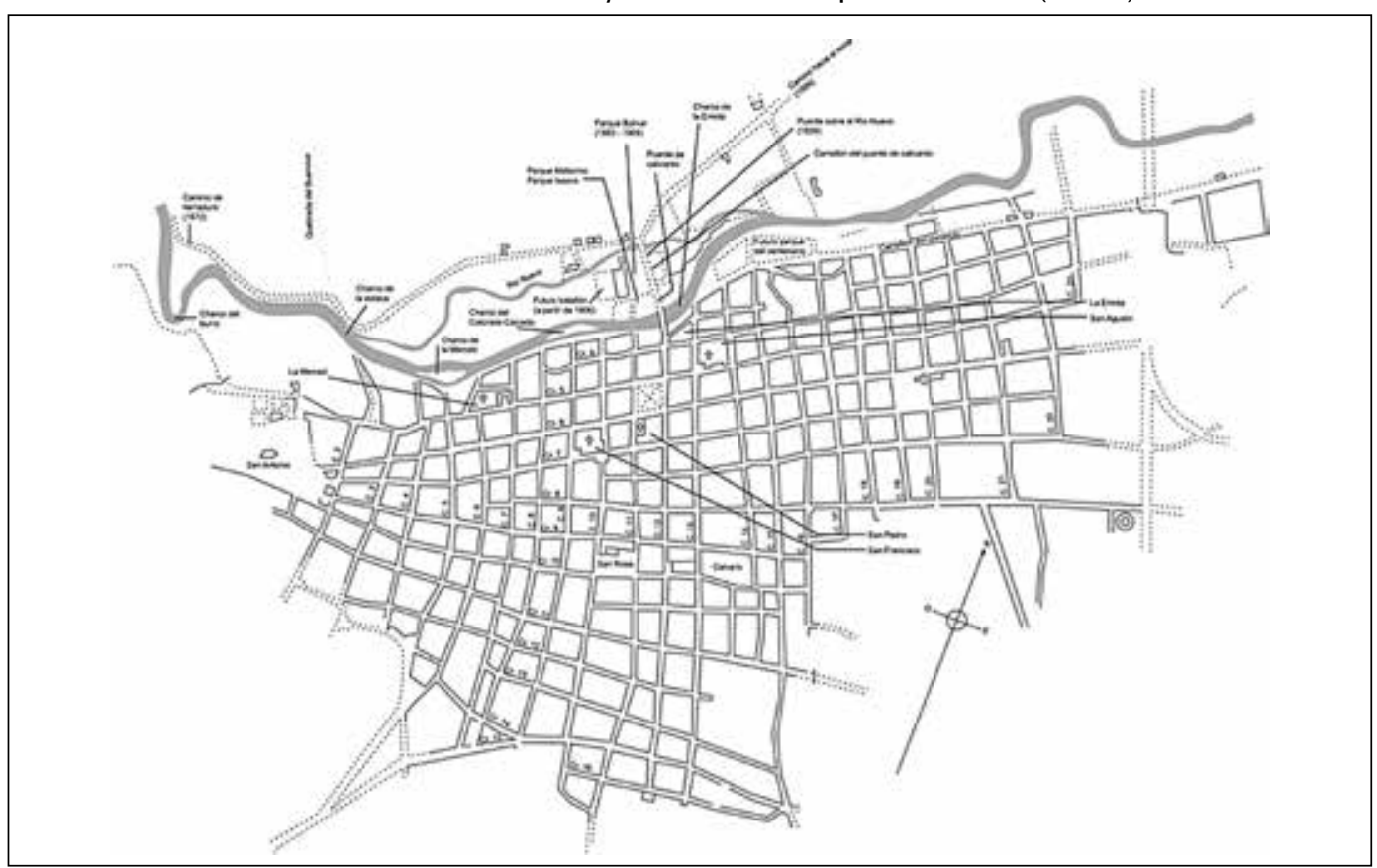

Fuente: Elaboración propia a partir del plano publicado en el periódico El Día (enero 1 de 1915) y del atribuido a Mario de Caicedo (1945). 
a la ciudad desde el norte podían dejar las bestias y los arreos al cuidado de un administrador (ElDía, 26 de abril de 1906). El diseño del edificio estuvo a cargo del ingeniero Enrique E. Alder, cónsul de Suiza en Cali (El Día, 23 de mayo de 1906), pero los planos probablemente fueron dibujados y desarrollados por el también ingeniero Aquilino Aparicio, formado en la Universidad Nacional de Colombia de donde se graduó en 1873 y quien a lo largo de su vida profesional adelantaría numerosos proyectos, entre los que se destacan la construcción de varios tramos del llamado Camino de Occidente y el cálculo estructural del puente metálico sobre el río La Vieja en inmediaciones de Cartago.

El proyecto para el edificio del batallón partía de un esquema bastante simple, conformado por una planta cuadrada constituida por cuatro pabellones organizados en torno a un único patio central, también cuadrado. Cada pabellón contaba con dos pisos y en cada una de las dos esquinas que se alzaban sobre la fachada principal se levantaría una torre ochavada a manera de garita. El área total estimada al inicio de la construcción era de $6.400 \mathrm{~m}^{2}$, lo que significa que el espacio ocupado por cada uno de los pabellones (en primer piso) rondaba los $800 \mathrm{~m}^{2}$.

La fachada principal (Figura 3) se organizaba simétricamente a partir de un cuerpo construido en piedra labrada que ostentaba sendos arcos de medio punto en cada uno de los dos pisos, flanqueados por pilastras adosadas al plano vertical del muro. Cornisas elaboradas con molduras simples separaban los pisos y un juego de almenas remataba los antepechos que pretendían delimitar la cubierta. Los dos cuerpos laterales repetían una sucesión de arcos de medio punto resaltados con molduras.
Seis cuerpos a cada lado concluían con una torre de planta cuadrada que se adelantaba al plano de cada fachada con fuerte predominio del lleno sobre el vacío y con reproducción de los arcos de medio punto como modelo en todas sus aberturas.

Se trataba de una composición bastante simple inspirada probablemente en instalaciones militares decimonónicas caracterizadas por la simetría bilateral y la austeridad decorativa. No deja de ser interesante que en uno de los listados de materiales adquiridos para la construcción del edificio (El Día, 24 de septiembre de 1907) quedara consignada la compra de un libro de arquitectura por valor de cuatro pesos. Giacomo Barozzi, llamado Il Vignola fue autor de Regola delli cinque ordini d'architettura, un libro publicado en 1562 y considerado como uno de los tratados de arquitectura renacentistas más difundidos gracias a las múltiples traducciones que se hicieron de él, incluso al castellano. Sus bellas láminas facilitaron su uso y propagación entre arquitectos y aficionados al mundo de la construcción. Probablemente con este libro se resolvieron algunos de los detalles relacionados con los remates de los muros, el trazado de los arcos y las molduras de las columnas.

Ya en el plano de lo constructivo, la primera piedra del edificio (concebido para albergar dos mil hombres) se puso el 20 de julio de 1906 como parte de las celebraciones del día de la Independencia. Sin embargo, solo en diciembre de ese año el Ministerio de Guerra aprobó una partida de $\$ 27.000$ pesos que se girarían a la ciudad en nueve pagos mensuales de $\$ 3.000$ cada uno, por lo que se puede deducir que los dineros invertidos en septiembre de 1906 (que ascendían a $\$ 483.68$ pesos según nota publicada en El Día el 9 de octubre de 1906) eran

Figura 3

Fachada del edificio para el Batallón Pichincha

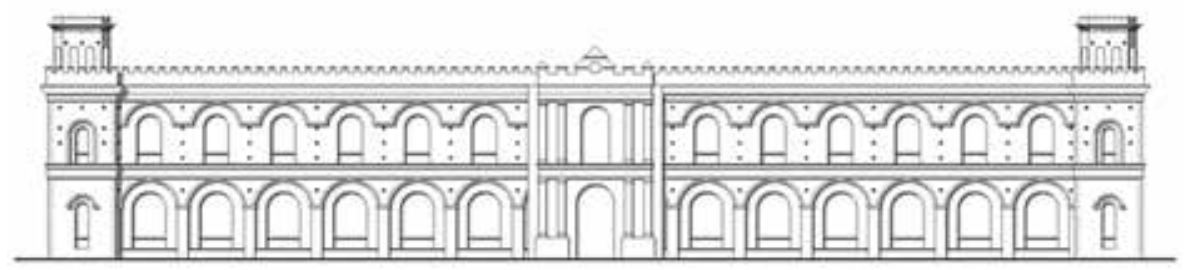

Fuente: elaboración propia a partir de información documental. Dibujo de Edwin Sotelo Zúñiga. 
a recursos cedidos por la municipalidad con el fin de asegurar el inicio de las obras.

Así, los trabajos más importantes empezaron en enero de 1907 tal como lo registró la prensa local (El Día, 5 de marzo de 1907) que durante los primeros meses no hizo más que alabar el rápido transcurrir de las obras encargadas al General Camilo Arana, entonces Inspector de Zapadores del Batallón 9 de Infantería. Para abril de ese año se habían terminado las cimentaciones (El Día, 9 de abril de 1907) cuya profundidad alcanzaba los tres metros con un ancho de dos metros y un volumen de $820 \mathrm{~m}^{3}$, suficientes para levantar el más firme y pesado edificio

El nombre de Camilo Arana ya estaba ligado a varios proyectos de importancia urbana entre los que se contaban la construcción de la casa municipal al servicio de los batallones acantonados en Cali, el cimiento para el muro de la verja de la Plaza de la Constitución (hoy Plaza de Caycedo), el acueducto público bajo la Calle del Comercio (hoy calle 12), la canalización del río Guachal, el diseño del Camino del Comercio (entre Cali y Palmira), la reparación de varias calles y andenes y muy especialmente la construcción de una muralla junto al río Cali (entre abril y diciembre de 1905 una primera etapa y posteriormente entre mayo y octubre de 1906 la segunda) elaborada con piedra de cantera y cal bajo su supervisión y con mano de obra del personal militar. En compañía de Arana estaba el General Lucio Velasco, entonces comandante de la zona militar acantonada en la ciudad e impulsor de varios proyectos paisajísticos para el entorno del río Cali. Su aporte más significativo al proyecto del Batallón tendría que ver con la capacitación de la mano de obra y con una incipiente sistematización de los procesos organizativos de la construcción.

Una importante fuente para conocer tales aspectos es el conjunto de once informes financieros del proyecto de construcción (publicados sucesivamente en El Día, el 9 de octubre de 1906, el 8 de enero, el 9 de abril, el 14 de mayo, el 9 de julio, el 27 de agosto, el 24 de septiembre, el 22 de octubre, el 26 de noviembre, el 24 de diciembre de 1907, el 28 de enero y el 26 de mayo de 1908), en donde aparecen discriminados los gastos ocasionados por el pago de jornales y la compra de materiales e insumos. De su sistematización y análisis se desprenden las siguientes conclusiones relativas a la manera en que se construía en Cali a comienzos del siglo XX.

El costo de la mano de obra en el período señalado, correspondió al $28.7 \%$ del costo total de la edificación. En ella se contabilizaban gremios de albañiles, carpinteros y canteros, principalmente, entre los cuales los albañiles recibían la mayor remuneración (una descripción detallada se puede apreciar en la Tabla 1). Es importante señalar que durante el período estudiado, el personal asalariado fue siempre el mismo: Ramón Collazos, Isaías Caicedo, Francisco Soto y Pedro Zúníiga actuaron como albañiles; Ernesto Gaviria fue el carpintero principal; Lisímaco Borda, Isaías López, Hipólito Echeverry y Antonio Nassar los canteros; Ignacio Rojas operaba como aserrador y Buenaventura Hernández era el alfarero. Según nota de la prensa local, todos ellos recibieron capacitación en la obra a la manera de lo que había ya ocurrido en Popayán durante la construcción del puente del Humilladero (Galindo y Paredes, 2008). (El Día, 19 de noviembre de 1907):

Tabla 1

Costo de la mano de obra en la construcción del edificio para el Batallón Pichincha a lo largo de un período de 11 meses (no consecutivos) comprendidos entre octubre de 1906 y abril de 1908

\begin{tabular}{|l|c|c|}
\cline { 2 - 3 } \multicolumn{1}{c|}{} & $\begin{array}{c}\text { Valor de los jornales recibidos en 11 meses no } \\
\text { consecutivos (en pesos) }\end{array}$ & $\begin{array}{c}\text { Relación porcentual con relación al costo } \\
\text { total de la mano de obra }\end{array}$ \\
\hline Albañiles & 849.46 & 40.31 \\
\hline Carpinteros & 380.37 & 18.05 \\
\hline Canteros & 347.50 & 16.49 \\
\hline Aserradores & 184.5 & 8.76 \\
\hline Alfareros & 24.00 & 1.14 \\
\hline Otros no especificados & 321.42 & 15.26 \\
\hline
\end{tabular}


[...] la mayor parte de los obreros que en ella trabajan [en la obra del Batallón] han sido educados, para el efecto, por el General y muchas veces contra la opinión de los mismos educandos, que creían no poder hacer lo que les enseñaba.

Adicionalmente, numerosos miembros del personal militar colaboraban en los trabajos de construcción, por lo que la obra llegó a ser vista como una escuela práctica de artes y oficios.

Por su parte, el costo de los materiales de construcción en el período señalado alcanzó una proporción equivalente al $71.28 \%$ del costo total de la edificación, correspondiéndole los ingresos más altos al señor Rudecindo Jaramillo (17.75 \%) quien suministraba las maderas aserradas para la obra. La lista de proveedores era extensa e incluía 115 nombres de personas naturales y algunas sociedades entre las que se destacan Bohmer \& Linzen (que facturó el $10.7 \%$ del total de insumos), Luis Fisher $(4.42 \%)$ y Burckhardt \& Co. $(2.47 \%)$.

Otro importante aspecto constructivo tiene que ver con la cadena de producción de materiales de construcción. Bajo el mando de Lucio Velasco se construyó un horno con el fin de abastecer de ladrillos la fábrica del edificio para el Batallón ( $E l$ Día, 23 de abril de 1907) situado a menos de un kilómetro de distancia. El horno medía cinco metros de altura por tres de diámetro, con un metro de cimiento, un metro de este a los arcos y tres metros de los arcos a las pilastras del techo. Tenía capacidad para quemar 2.300 adobes de cuarenta centímetros de largo por dieciocho de ancho y ocho de grueso. La enramada tenía dos metros de altura por cinco de diámetro y el corredor que lo rodeaba tenía 26 metros de largo y $40 \mathrm{~cm}$ de longitud por tres metros de ancho. La enramada del galpón medía $27 \mathrm{~m}, 60 \mathrm{~cm}$ longitudinales por 10 $\mathrm{m}$ de ancho y su altura a la solera era de $2 \mathrm{~m} 70 \mathrm{~cm}$.

A los ladrillos, tejas y adobes fabricados a pie de obra se sumaban piedras sacadas del río para la construcción de los cimientos, almudes de cal, guaduas, chontas, maderas labradas, piedras de cantera (cercana también a las obras), carbón mineral, hierro en rieles y el llamado cemento romano, como entonces se denominaba al cemento tipo Portland importado de Europa. Adicionalmente, la obra contaba con un tanque para envenenar maderas y un vivero en donde se cultivaban los árboles destinados a sembrarse en los parques aledaños $(E l$ Día, 19 de noviembre de 1907).
En cuanto a la organización de los trabajos, el mismo periódico (ElDía, 3 de diciembre de 1907) en una crónica de Miguel Valencia describía detalladamente el modelo impuesto por Lucio Velasco:

Los trabajos se llevan a cabo por el Batallón $9^{\circ}$ de Infantería acantonado en la ciudad. Este cuerpo ha sido dividido en secciones por el mismo Jefe nombrado antes y cada sección la preside un Oficial. Todos los días cada Comandante de sección da al Jefe del Cuerpo cuenta de los trabajos ejecutados por ésta y el citado Jefe transmite, diariamente también y por escrito, el parte general al señor General Lucio Velasco.

Adicionalmente, se llevaba una completa bitácora en la cual se consignaban las actividades del personal (tanto jornaleros como militares) y se dejaba clara constancia de los rendimientos de mano de obra (El Día, 3 de diciembre de 1907):

El maestro López talló ciento sesenta tejas comunes; el Sargento Martínez y el Cabo Lozano tallaron setenta y cinco tejas para caballete y cincuenta y cinco planas; un soldado apilando material; otro en la cimbra; el Cabo Holguín y un soldado quemando material; los Soldados Toba, Zúńiga y Lerma hicieron cuatrocientos setenta adobes grandes; cinco Soldados preparando barro.

Así:

[...] Reuniendo los partes diarios, tan detallados y ordenados como se ve, se puede saber con entera certeza cuántas piedras se emplearon, v.g., en los cimientos, o cuántos ladrillos en la edificación, cosa que dará a ver con excepcional exactitud el costo de la obra. Esto sí puede llamarse organización seria y estadística completa.

Este modelo organizativo funcionaría al menos en los dos primeros ańos. En 1908 el señor Gonzalo Naranjo fue nombrado inspector de los trabajos de construcción del cuartel, con una asignación mensual de $\$ 62$ pesos (El Día, 14 de abril de 1908) aunque a partir de entonces las obras disminuyeron en su ritmo, no solamente a causa del lento flujo de los fondos sino también por las opiniones desfavorables al proyecto emanadas de funcionarios del Ministerio de Guerra (Arango, 1913, p.18):

Si no se vuelve a incurrir en el error de pretender que los cuarteles, como sucede con el que actualmente se construye en Cali, sean verdaderas fortalezas militares, ya que este no es su objeto, y si se adoptan 
métodos modernos de construcción, me atrevo a creer que con una partida igual a la que hoy se destina para arrendatarios y reparaciones, se lograría, en el curso de pocos ańos, dotar a la Nación de cuarteles cómodos en las poblaciones que forzosamente han de ser acantonamientos de tropas.

Noticias fragmentarias dan cuenta de continuas interrupciones en el proceso edificatorio a tal punto que al momento de fallecer el general Lucio Velasco el 18 de febrero de 1925, se contaba tan solo con el $50 \%$ del área del primer piso terminada, aunque la fachada principal había alcanzado la totalidad de su altura, tal y como lo muestra una foto tomada hacia 1927 (Figura 4). Un informe de 1929 (Abadía, 1929, p. 45) daba cuenta del estado de las obras:

Cuartel de Cali. Para la terminación de este edificio que será un cuartel modelo, falta por levantar la mitad del claustro principal y construir las dependencias para las cocinas, enfermería, baños, excusados y caballerizas.

Otro informe, fechado esta vez en 1930 (Congreso Nacional de Colombia, 1930, p. 136) expresaba que los trabajos en la construcción del cuartel de Cali están suspendidos por falta de fondos destinados a ese objeto y desde hace mucho tiempo:

[...]. En este mismo informe se comentaba que el edificio del Cuartel haría uso del cauce de la quebrada del río Nuevo para la construcción de su alcantarillado.

Con toda seguridad que la celebración de los 400 años de fundación de la ciudad de Cali, en 1936, reanimaron la culminación de lo empezado. En

Figura 4

Fachada principal del edificio del cuartel en proceso de construcción (1927)

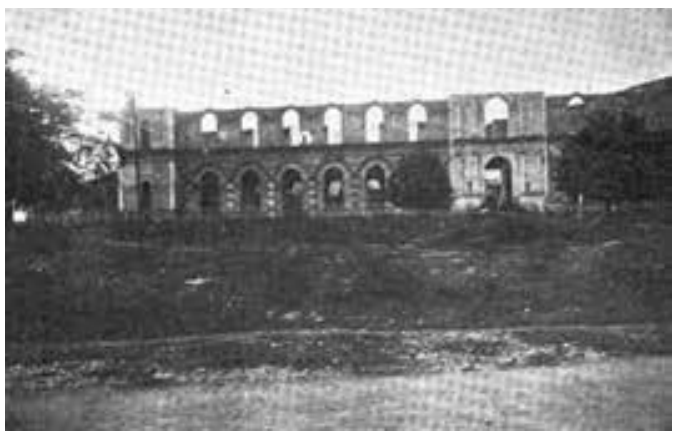

Fuente: Biblioteca Departamental Jorge Garcés Borrero, archivo A639.JPG, Cali.
Ministerio de Guerra (1933, p. 77), por ejemplo, se menciona que desde la institución se ha practicado una visita al edificio para estudiar el presupuesto que debe destinarse a continuar la obra que está suspendida hace varios años y se esperan propuestas para contratar una reparación total de la azotea [...]

En julio de 1939 el comando de la Tercera Brigada decidió trasladarse enteramente desde Popayán a Cali. Para entonces el edificio contaba con una cubierta plana (Figura 5) que cerraba la totalidad del segundo piso, construida de tal manera que el conjunto guardaba la apariencia de un bloque compacto en forma de "U", con un patio interior que servía de espacio para ejercicios militares, depósito de enseres e incluso fue la primera sede del cuerpo de bomberos voluntarios. Una fotografía tomada a finales de la década de 1930 en dirección occidente-oriente (Figura 6) permite apreciar el edificio al término de su primera fase de construcción, las escaleras sin madera que llevaban al segundo piso y los cobertizos bajos que cerraban el patio principal.

\section{La reconfiguración del entorno del río Calí entre 1918 y 1936}

La construcción del edificio para el cuartel animó desde sus comienzos la culminación de la Plaza de Bolívar que se extendía frente de su fachada principal. Según la prensa local (El Día, 28 de agosto de 1906), el Concejo cedió el mismo año de comenzadas las obras una fuente ornamental que estaba en la plaza de San Pedro, y don Guillermo Chávez obsequió otra igual a fin de que

\section{Figura 5}

Cubierta del edificio del cuartel en 1932

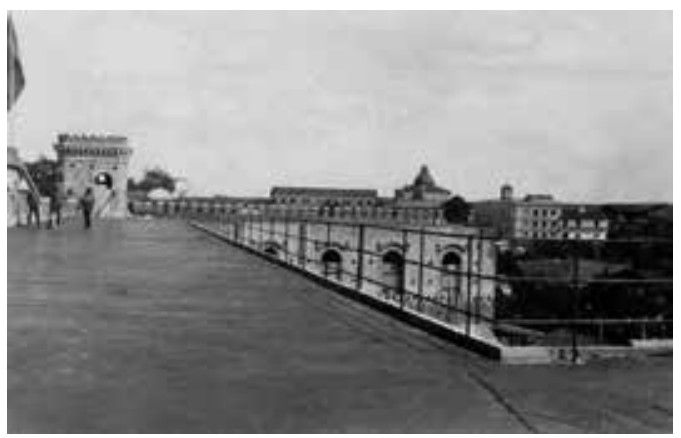

Fuente: Biblioteca Departamental Jorge Garcés Borrero, archivo 0100382.JPG, Cali. 
Figura 6

Vista del conjunto desde el occidente (c.a. 1939)

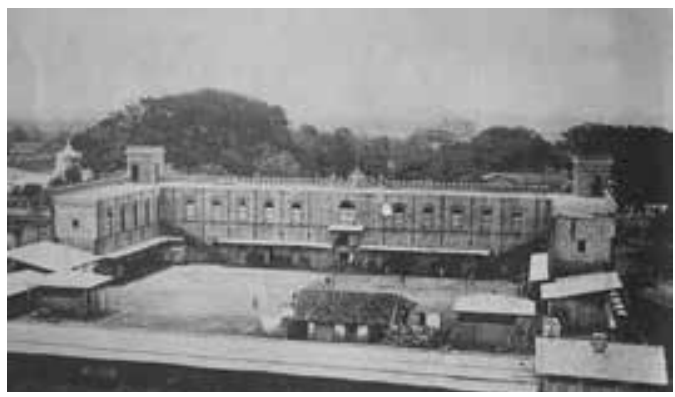

Fuente: Colección particular.

fueran dispuestas en el nuevo espacio urbano. Sin embargo, la entrega formal de este nuevo espacio público a la ciudad solo se haría realidad el 20 de julio de 1907 por parte del propio Lucio Velasco al señor Evaristo García en calidad de presidente del Concejo. Durante los años siguientes este lugar haría las funciones de plaza de armas al personal acantonado en el cuartel (Figura 7).

Se trataba de un lugar claramente delimitado por los ríos Cali y Nuevo (al sur y al norte, respectivamente), la fachada principal del edificio del Cuartel por el occidente, y por el oriente una inmensa área de terreno de propiedad del señor Adriano Martínez, y más atrás la casa destinada al manicomio y algunas casas de habitación. Lo atravesaba el camellón del puente de calicanto y se nutría de una arborización que se mantuvo sin mayores cambios hasta 1918 cuando el tablero del puente sufrió cambios importantes, que consistieron en la colocación de rieles de acero dispuestos perpendicularmente al eje longitudinal y un aumento del ancho útil de la estructura lo cual permitió desde ese momento el tránsito de automóviles. Inmediatamente después empezaría

Figura 7

Fachada principal del edificio del cuartel y la Plaza de Bolívar

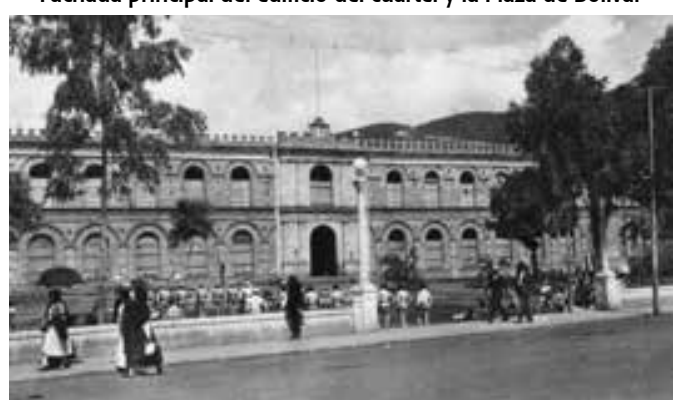

Fuente: Colección particular. a bosquejar el denominado Paseo del Libertador a partir del anterior Paseo de Las Ceibas y la nueva estatua de Simón Bolívar, su más importante y preciado hito, fue puesta en su sitio en 1921 (Figura 8).

Al compás con la terminación de los trabajos de ampliación del puente la ciudad empezó a preparase para un proceso de profundas transformaciones arquitectónicas y urbanas. A la vez que se hacía el acueducto metálico y se reparaban las alcantarillas, se empezaba también la construcción del Teatro Municipal y se iniciaba un ambicioso plan de nuevas avenidas apoyándose en lo que llamarían el plano del Cali futuro, encargado por concurso desde el Concejo mediante el Acuerdo 18 del 5 de noviembre de 1918 (Gaceta Municipal de Cali, No. 194, 15 de diciembre de 1918). El proyecto escogido debería indicar entre otras cosasla amplitud de las calles, plazas, parques y avenidas y señalar los sitios adecuados para la construcción de templos, escuelas, teatros, mercados y puentes que unan la parte norte con el centro de la ciudad, es decir, adelantándose a los procesos de ocupación urbanística que darían pie a la conformación y la urbanización proyectada por los señores López \& Gómez en la ribera izquierda del río Nuevo, aprovechándose de las facilidades de comunicación que sobre sus tierras ofrecía el puente de mampostería recién ampliado. La ciudad, por fin, empezaba su proceso de expansión hacia el norte.

Otro hecho importante relacionado con la transformación del lado norte del puente de calicanto fue la construcción en 1926 de la planta industrial de la Cervecería Alemana sobre un predio ubicado en la margen izquierda del río Cali y contiguo al edificio del batallón. Como bien lo ha explicado Hincapié (2000), su implantación hizo

Figura 8

El Paseo del Libertador en 1925

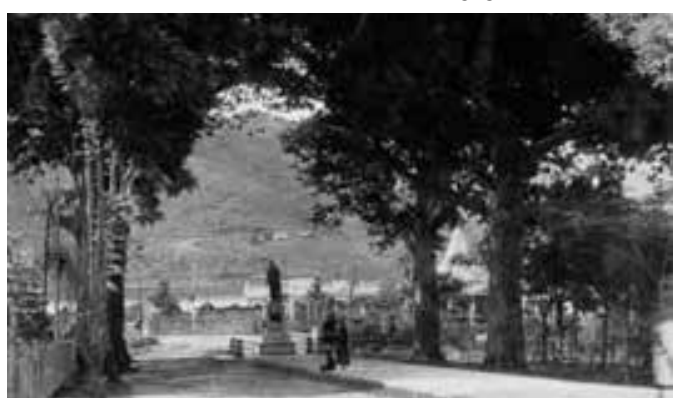

Fuente: Biblioteca Departamental Jorge Garcés Borrero, archivo 0201204.JPG, Cali. 
necesaria la construcción de un puente metálico sobre el río Cali a la altura de la Calle Octava que comunicaba la fábrica con el centro de la ciudad e impulsó la construcción de la llamada Avenida Pichincha situada entre la misma planta y el Paseo del Libertador. El entorno del puente de mampostería ganaba así nuevas calles e iba definiendo el futuro de su orilla norte. La cervecería cedió un terreno para usos deportivos de carácter público (club de tenis) y el parque Mallarino (que de ser propiedad de la Nación pasó al dominio municipal) se convirtió en el lugar perfecto para disponer en él un monumento a Jorge Isaacs. El circuito se completaría con la construcción del puente España en 1937 que conectó la Avenida Pichincha (Figura 9) con el centro de la ciudad y salvaba el río Cali de manera perpendicular.

El Paseo del Libertador o Paseo Bolívar se complementaría con la transformación de la Avenida Boyacá (llamada Avenida Belalcázar a partir de su inauguración) acontecida entre 1934 y 1936 como parte de las celebraciones del cuarto centenario de la fundación de la ciudad. Hasta entonces, se trataba de una vía estrecha y sin pavimento que transitaba sobre el piedemonte de los cerros de la ciudad en dirección oeste y buscaba el empinado ascenso hacia la vía al mar. La nueva avenida arrancaba al término del Paseo Bolívar y terminaba en el cruce de la Calle 4 con Carrera 4 completando un circuito así descrito por los ingenieros a cargo de la obra, Vicente Aragón y Jorge Quintero (Anónimo, 1935):

La nueva vía asciende por la margen izquierda del río Cali, en una extensión de 2 kilómetros hasta el río "Aguacatal"; continúa ascendiendo por la margen

Figura 9

Avenida Pichincha junto al costado sur del edificio del cuartel. Al fondo las instalaciones de la Cervecería Alemana (1932)

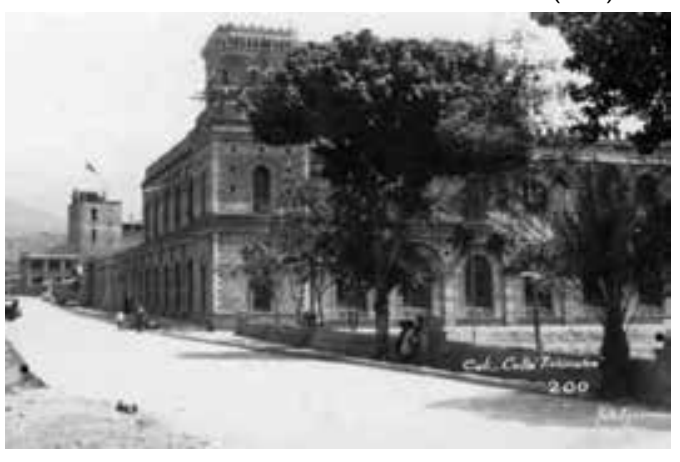

Fuente: Biblioteca Departamental Jorge Garcés Borrero, archivo 0501361.JPG, Cali. derecha del mismo río Cali, hasta llegar a la parte más alta, en el sitio conocido tradicionalmente por el "Charco del burro", y de allí desciende por la hoya del la quebrada del Arco, hasta entrar a la ciudad por la carrera $4^{a}$, completando así un recorrido de 4 kilómetros.

El plano que en el mismo artículo incluyen sus autores (Figura 10) deja ver con claridad el puente de albañilería y su entono más inmediato: el Batallón Pichincha, el Paseo del Libertador, la Avenida Pichincha y el cauce del río Nuevo, entre otras cosas. De manera lenta pero sostenida, se fue entonces transformando el entorno inmediato del puente de mampostería: de ser un remate de la Calle 12 en busca de un camino provincial, el puente pasó a ser el objeto más importante de un eje longitudinal que prolongaba la ciudad hacia unos terrenos urbanizables, corazón de un espacio público pensado para el goce y punto de confluencia de nuevas vías que sintetizaban los sueños de la ciudad: pasando el puente se tomaban los caminos al mar y a Yumbo y sobre su extremo sur concluía la vía que llevaba a la Estación del Ferrocarril.

\section{Los años postreros (1936-1968)}

A partir de 1936 empieza el proceso de consolidación urbana del norte de la ciudad y nuevas vías juegan un papel importante. El viejo camino a Yumbo, llamado ahora avenida Ayacucho, poco a poco se va transformando en una próspera calle que combina actividades residenciales y comerciales (hoy avenida sexta). De forma paralela a la rivera sur del río Cali se construye la avenida Colombia, lo que obliga a delimitar las manzanas conformadas entre la carrera 3 y el borde del río. Se construye el puente España como prolongación de la calle octava hacia la avenida Belalcázar de tal manera que la Avenida Pichincha (que pasa por el costado sur del edificio del Batallón) conecta este puente por el lado norte del río con el puente Ortiz. Finalmente, aguas abajo se levanta el puente Alfonso López (prolongación de la Calle 15), también sobre el río Cali, lo que facilitó aún más la comunicación entre el centro de la ciudad y los nuevos barrios del norte en proceso de construcción (junto a él se construirá el cuartel de bomberos ). 
Figura 10

Reconstrucción del entorno inmediato al edificio del Batallón Pichincha (c.a. 1936)

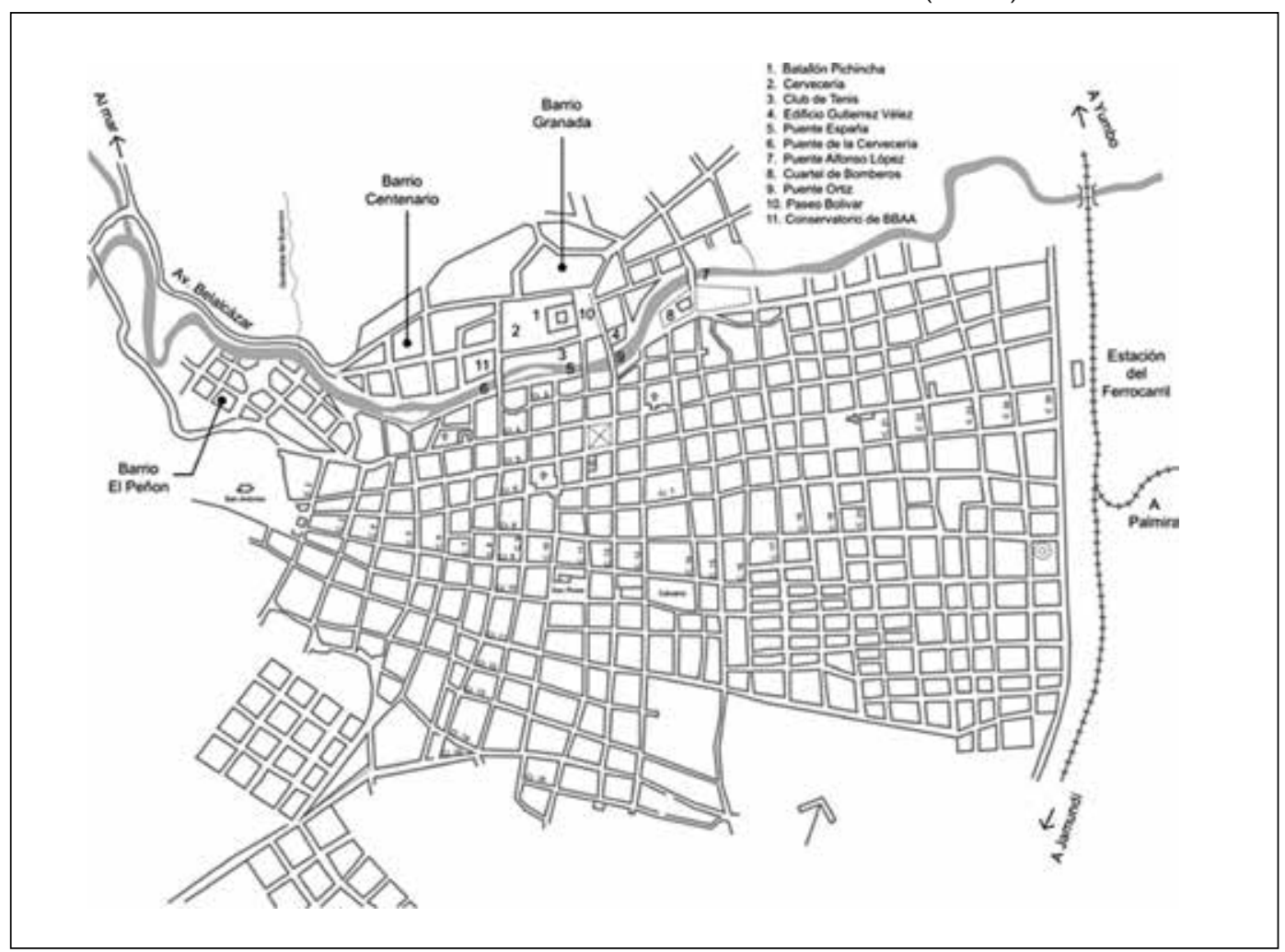

Fuente: Elaboración propia a partir de artículo publicado en revista PAN, No. 4, noviembre de 1935, pp. 30-42.

Nuevos barrios surgirán en torno a estas vías: Granada (1922), Centenario (a partir de 1937), Versalles (1935), Juanambú (1937), Santa Mónica (1940) y Santa Rita (1945) irán poblando la zona comprendida entre el río y el pie de los cerros de la cordillera Occidental. En el entorno inmediato al edificio del Batallón Pichincha es importante destacar el papel desempeñado por el edificio $\mathrm{Gu}$ tiérrez Vélez y las edificaciones que conformaban el club de tenis Cali. El primero estaba situado en la esquina nororiental del puente Ortiz (antes puente de calicanto) y ayudaba a delimitar acertadamente el espacio que conformaban el paseo Bolívar y el parque de Las Ceibas. Por su parte, el club de tenis Cali inaugurado en 1928, estaba situado sobre la avenida Pichincha y ocupaba el predio existente entre la ribera norte del río Cali y la fachada sur del edificio del Cuartel. Sus edificaciones se mantendrían en pie hasta 1968 cuando se dio paso a la demolición de toda el área urbana a fin de dar paso a la construcción del Centro Administrativo Municipal (CAM), autorizado mediante el Acuerdo 023 de 1965 del Concejo de Cali.
Al momento de su demolición el edificio del Batallón Pichincha había completado la construcción de todos sus pabellones, tenía dos pisos de altura y había cerrado por completo el patio central (Figura 11) y reemplazado la cubierta plana por planos inclinados a una sola agua. Su masa imponía un equilibrio con los volúmenes del otro lado del río a la vez que su fachada principal servía de límite a los arbolados paseos que prolongaban los puentes Ortiz y España.

Figura 11

Edificio del Batallón Pichincha y su entorno en 1968

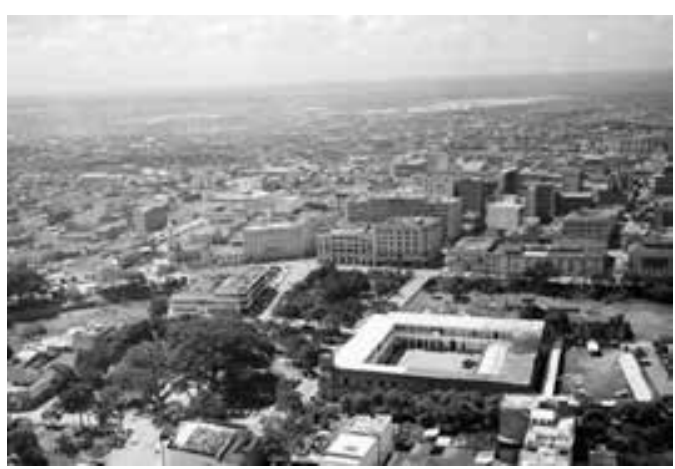

Fuente: Archivo particular. 


\section{Bibliografía}

\section{Fuentes documentales:}

- Archivo Histórico de Cali: Actas del Concejo, 1830-1850.

- Gaceta Municipal de Cali, 1920-1930.

\section{Periódicos y revistas locales:}

- Correo del Valle (1904).

- El Día(1909).

- El Cauca (1897).

\section{Fuentes secundarias:}

- ABADÍA MÉNDEZ, Miguel (1929). Mensaje del presidente de la República al Congreso Nacional. Bogotá: s.i.

- ANDRÉ, Edouard (1884). América pintoresca. Barcelona: Montaner y Simón.

- ANÓNIMO (1978). "Historia de la III Brigada". Boletín de la Academia de Historia del Valle del Cauca. Nos. 171-172. pp. 323-324.

- ANÓNIMO (1935). “Una nueva avenida para Cali”. Revista PAN. No. 4. pp. 30-42

- APRILE, Jacques (1991). La ciudad colombiana (v. 1). Bogotá: Biblioteca Banco Popular.

- APRILE, Jacques (2010). La ciudad colombiana (v. 4). Cali: Programa editorial de la Universidad del Valle.

- ARANGO, José Manuel (1913). Informe presentado por el Ministro de Guerra al Congreso Nacional de 1913. Bogotá: Talleres del Estado Mayor General.

- BUENAVENTURA, Manuel María (1957). Del Cali que se fue. Cali: Imprenta departamental.

- COLMENARES, Germán (1976). Cali: terratenientes, mineros y comerciantes. Cali: Universidad del Valle.

- CONGRESO NACIONAL DE COLOMBIA (1930). Historia de las leyes (vol. 12). Bogotá: Imprenta Nacional.

- GALINDO, Jorge y PAREDES, Jairo (2008). Puentes de arco de ladrillo en la región del alto Cauca. Una tradición constructiva olvidada. Bogotá: Universidad Nacional de Colombia.

- HINCAPIÉ, Ricardo (2000). "Puentes antiguos sobre el río Cali". Revista CITCE. No. 3. pp. 3-30.

- HOLTON, Isaac (1851/1981). La Nueva Granada: veinte meses en los Andes. Bogotá: Banco de la República.

- MINISTERIO DE GUERRA (1933). Memoria que el Ministro de Guerra presenta al Congreso de 1933. Bogotá: Secretaría de Gobierno y Guerra.

- PALACIOS, Belisario (1896). Apuntaciones histórico - geográficas de la provincia de Cali. Ibagué: Imprenta del departamento.

- PÉREZ, Felpie (1863). Jeografía física i política del Estado del Cauca. Bogotá: Imprenta de la Nacion.

- RIVERA Y GARRIDO, Luciano (1886). Algo sobre el Valle del Cauca. Impresiones y recuerdos de un conferencista. Buga: Imprenta a cargo de R.A. Pastrana.

- VÁSQUEZ, Edgar (1982). Historia del desarrollo en Cali (hasta el siglo XIX). Cali: Universidad del Valle.

- VÁSQUEZ, Edgar (2001). Historia de Cali en el siglo 20. Cali: Artes gráficas del Valle. 